STUDI

FRANCESI

\section{Studi Francesi}

Rivista quadrimestrale fondata da Franco Simone

188 (LXIII | II) | 2019

Penser/peser le Moyen Âge entre XVe et XVIIe siècle:

parcours de recherche - sous la direction de Maurizio

Busca et Piero Andrea Martina

\title{
David Moucaud, La mesure du badin: pour une infrastylistique de l'élegance marotique
}

Filippo Fassina

\section{(Q) OpenEdition \\ Journals}

\section{Edizione digitale}

URL: http://journals.openedition.org/studifrancesi/19627

DOI: $10.4000 /$ studifrancesi. 19627

ISSN: 2421-5856

\section{Editore}

Rosenberg \& Sellier

\section{Edizione cartacea}

Data di pubblicazione: 1 août 2019

Paginazione: 346-347

ISSN: 0039-2944

Notizia bibliografica digitale

Filippo Fassina, «David Moucaud, La mesure du badin: pour une infrastylistique de l'élegance marotique», Studi Francesi [Online], 188 (LXIII | II) | 2019, online dal 01 février 2020, consultato il 25 janvier 2021. URL: http://journals.openedition.org/studifrancesi/19627 ; DOI: https://doi.org/10.4000/studifrancesi. 19627

Questo documento è stato generato automaticamente il 25 janvier 2021.

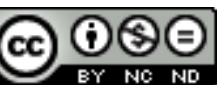

Studi Francesi è distribuita con Licenza Creative Commons Attribuzione - Non commerciale - Non opere derivate 4.0 Internazionale. 


\section{David Moucaud, La mesure du badin: pour une infrastylistique de l'élegance marotique}

Filippo Fassina

\section{NOTIZIA}

David Moucaud, La mesure du badin: pour une infrastylistique de l'élegance marotique, "Le verger - bouquet XIV" (novembre 2018), en ligne, 19 pp.

1 Una delle caratteristiche fondamentali dello stile di Marot è l'uso di alcuni marcatori che permettono di abbassare il livello sintattico ed enunciativo, dando vita a quel sermo humilis che rende unica la sua scrittura. L'A. analizza dunque dal punto di vista lessicale e sintattico le scelte effettuate da Marot per dare ai suoi testi quella sobria eleganza e quello stile familiare che li contraddistingue: in primo luogo, i cosiddetti modifieurs de l'intensité basse. Si tratta di avverbi quali peu, petit oppure trop, bien, di negazioni o di falsi comparativi (plus...que, comme) che hanno la funzione di smorzare e rallentare il ritmo della narrazione, per creare questo effetto, che l'A. definisce un elegante abbassamento del livello stilistico. In secondo luogo, Marot opera una sorta di controllo misurato dei versi, il quale conferisce ai suoi componimenti una brevitas e una precisione rigida e referenziale. Si tratta di una tecnica, mutuata dai Grands rhétoriqueurs, che consiste nel comporre versi alla maniera della litania, del serventois o del chant royal, con una perifrasi regolarmente ordinata all'interno della sezione, creando una vera e propria formula ricorrente che spezza il ritmo. Infine, viene sottolineato come tutte queste tecniche vengano utilizzate in maniera combinata e interscambiabile fra loro, tanto che lo studio delle varianti fra un'edizione e l'altra dell'Adolescence permette di comprendere in maniera ancora più evidente il lavoro che Marot compie sui suoi testi. Lo stile dunque, in apparenza semplice, è in realtà frutto di 
una costruzione ricercata che trasmette al lettore l'idea di limpidezza e naturalezza tipiche del sermo humilis di Marot. 